with concurrent Capgras and koro we all pray will turn up!

LEWrs. S. (1991) The right stuff? A prospective controlled trial of trainees' research. Psychiatric Bulletin. 16, 478480.

Flanigan, P. (1992) Junior publications in the British Journal of Psychiatry. Psychiatric Bulletin, 16, 518.

ANDREW SMITH, West London Healthcare NHS Trust, Uxbridge Road, Southall, Middlesex UB1 3EU

\section{Criteria for compulsory hospital admission}

Sir: I am puzzled by J. H. M. Crichton's article on the revised Code of Practice for the Mental Health Act, 1983 (Psychiatric Bulletin, January 1994, 18, 45-46). He says that Chapter 2 about assessment and admission specifies "that a patient may be admitted because of danger to others even without danger to the patient's own health and safety".

This is nothing new. What is new is the point underlined by Ministers in the Foreword to the Code, that risks to their own or other people's safety are not the only criteria for patients' admission, and that they may be detained in the interests of their own health, OR safety, OR for the protection of others. Only one of these grounds needs to be satisfied.

Members of the National Schizophrenia Fellowship have been concerned for a long time that some psychiatrists do not appear to know what the criterla for compulsory admission are. It is very disappointing that an article devoted to the revised Code does not pick up the change of wording specially introduced to clarify this point.

DOROTHY SILBERSTON, Vice-Chairman, National Schizophrenia Fellowship, 28 Castle Street, Kingston-upon-Thames, Surrey KT1 1SS

Sir: I am grateful to Dorothy Silberston for raising an important point about the Department of Health's new guidance on the use of the criteria for compulsory hospital admissions.

It was not implied, however, in the paper on the revised Code of Practice that there was any change in the criteria for compulsory admission. which would of course require change in statute law. It is clear from the references in the paper that it was based on the Code of Practice laid before Parliament on the 19 May 1993; it was written and submitted before the Code was published. There was no opportunity to comment on the Secretary of State's foreword which was not included in the Parliamentary copy.

I think Dorothy Silberston is mistaken in her view that psychiatrists do not know the criteria for compulsory admission. The conclusion of the paper comments on this point. It is clear that the criteria for admission have been more clearly 'spelt out' not only in the revised code but in its foreword and in press releases from the Department of Health. The purpose of this new emphasis I think is less about informing psychiatrists about admission criteria and more about persuading psychiatrists to lower their threshold when considering if a patient fulfils compulsory admission criteria. This point is further elaborated in a paper soon to be published (Crichton, 1994).

CRICHTON, J.H.M. (1994) Supervised discharge. Accepted Medicine Sctence and the Law.

JOHN H. M. CRICHTON, University of Cambridge, Institute of Criminology, 7 West Road, Cambridge CB3 9DT

\section{Continuing medical education}

Sir: May I extend the comments on continuing medical education (Sensky, Psychiatric Bulletin, January 1994, 18, 18-21, and Ferrier \& Cooper, Psychiatric Bulletin, January 1994, 18, 43-44).

Continuing medical education for consultants and non-trainee psychiatrists should include regular reviews of developments in the other branches of medicine and surgery. Could the College consider commissioning general review lectures of recent developments in various medical disciplines for the Annual Meeting?

D. M. HAMBIDGE, Royal Air Force Outpatients Department, Nocton Hall, Nocton, Lincoln LN4 2AA

Sir: I agree with the thrust of Dr Hambidge's letter although I would need some convincing about the reevance of surgery. I think a better format for this than large review lectures during College meetings would be:

(a) update one day courses for a maximum of 30 consultants on the topic, endocrinology and psychiatry

(b) articles on the same type of topics in the new College Journal for "continuing professional development of consultants, Advances in Psychiatric Treatment'. We will plan to act on this.

A. C. P. SIMS, Chairman, Committee on Continuing Medical Education, Royal College of Psychiatrists

\section{Label of personality disorder}

Sir: I was disappointed with the letters in response to Dr Steadman's article (Psychiatric 
Bulletin, 1993, 17, 774) 'Personality disorder a declining diagnosis'. In the present 'politically correct' climate the diagnosis of personality disorder seems very 'non-PC'.

Its use as a means of labelling an annoying patient is indefensible - but properly used it can give much information about past, present and future behaviour. Just as all diagnoses are 'labels' they give more information, not less, enabling one to make informed management decisions, taking advantage of previous assessments and experience.

Perhaps the answer, as with many non-PC terms, is to change the name. Personality Challenged or Otherwise Personality Gifted, are two possibilities although I would be pleased to hear other suggestions.

Caroline Mulligan, Windsor Day Hospital, Llverpool

\section{The value of child and adolescent psychiatry}

Sir: Dr Hermson (Psychiatric Bulletin, 1993, 17. 628) and Dr Kirby (Psychiatric Bulletin April $1994,18,246$ ) both emphasise the value of early experience in child and family psychiatry as part of the training for all psychiatrists.

Some years ago Peter Hill and I published an article making similar arguments (Bulletin of the Royal College of Psychiatrists, 1987, 11, 19-21).
We pointed out that approximately one quarter of the population is under the age of 18 and that this group has an appreciable psychiatric morbidity. All psychiatrists should known about this and about the services available for children and families. We suggested that all psychiatrists in training would benefit from a child psychiatry placement, as senior house officer or registrar. Useful training experiences would include practice at taking a developmental perspective in formulating problems, opportunities to interview the developmentally young and take part in conjoint family interviews, working within a service which emphasises the wider family and social context of patients, observing and taking part in a wide range of psychological treatment methods, and participating in a multidisciplinary team. We suggested that child psychiatrists should structure training differently for trainees who do not intend to pursue a career in child and adolescent psychiatry and provided a checklist of training opportunities.

Experience in child and adolescent psychiatry is just as relevant today for future adult psychiatrists as it was when we wrote the article. It is of interest that trainees too support the value of child and adolescent psychiatry irrespective of future psychiatric career. Clinical tutors and the central approval panel should take note.

DAVID COTTRELl, Untuersity of Leeds, $12 a$ Clarendon Road, Leeds LS2 9NN

\section{Corrigendum}

The names of the authors of the letter 'Age and sex differences in general practice benzodiazepine prescription in United Kingdom'
(Psychiatric Bulletin, 18, 376-377) should read: V. Eapen. N. Savla and A. Khan. 